\title{
キンチャクダイの卵発生と仔魚期
}

\author{
藤 田 矢 郎・水 戸 敏 \\ (1959 年 12 月 15 日受理)
}

\section{EGG DEVELOPMENT AND HATCHED LARVAE OF A CHAETODONTID FISH, CHAETODONTOPLUS SEPTENTRIONALIS}

\author{
(TEMMINCK et SCHLEGeL)
}

\section{Shiro Fujrta and Satoshi Mrto*}

Chaetodontoplus septentrionalis (TEMMINCK et SCHLEGEL) is a common chaetodontid fish, distributed from the middle to southern Japan, Formosa and China.

The spawning season seems to extend from July to early September in the western part of Yamaguchi Prefecture.

On August 12 and 25, 1959 the authors carried out the artificial insemination of this fish and observed the egg development and hatched larvae at Tsunoshima, Hohoku Cho, Yamaguchi Prefecture.

The egg is colorless and buoyant, spherical in shape measuring $0.82 \sim 0.88 \mathrm{~mm}$ in diameter with a single oil globule measuring $0.15 \sim 0.20 \mathrm{~mm}$. The yolk is roughly segmented near its animal pole.

Hatching took place in 16 hours at the water temperature of $26.8 \sim 28.0^{\circ} \mathrm{C}$ and in 22 hours and 40 minutes at $24 \sim 26^{\circ} \mathrm{C}$.

Newly hatched larvae (including the one of Fig. 1, i) were $1.9 \sim 2.0 \mathrm{~mm}$ in total length, with the oil globule situated at the posterior part of the elongated oval-shaped yolk sac. The myotome number was $12+15=27$ (vertebral number of this fish being $10+14=24$ ). The melanophores were scattered all over the body excepting the end part of the tail and on the surface of the oil globule. The larvae were free from the xanthophores.

In 22 hours, the eyes became slightly pigmented. The xantophores appeared on the oil globule and on the yolk around it, none on the body. The melanophores on the oil globule shifted to the anterior part of the yolk. The number of myotomes was $10+15=25$.

In 48 hours, the yolk and oil globule were almost consumed and the larva attained $2.6 \mathrm{~mm}$ in total length. The mouth was formed, and pectoral fins well developed. The melanophores became larger and covered the body excepting the tail end.

In 68 hours, the yolk were entirely consumed and the larva died.

キンチャクダイ**Chaetodontoplus septentrionalis (TEMMINCK et SCHLEGEL) はチョウチョウウオ 科 Chaetodontidae K屈し，本邦中部以南から台湾，支那海儿分布する温熱带性の沼岸焦である。

チョウチョウウオ科魚類の産卵については, サザナミヤッコ属の1種 Pomacanthus arcuatus について

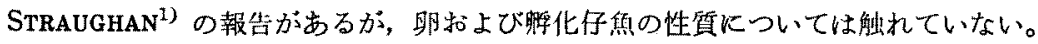

また，本科焦類のうちには幼期に特異な形をした Tholichthys stage を経過するものがあり，かが国産

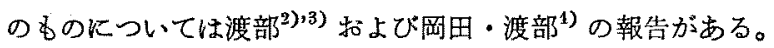

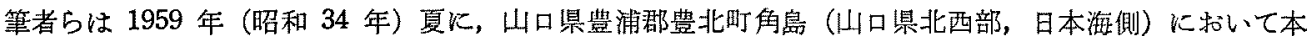

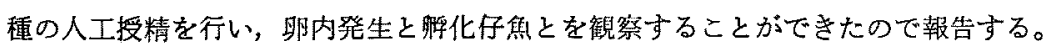

* 九州大学辳学部水産学教室 (Fish. Lab. Fac. Agr., Kyushu Univ., Fukuoka City). 本研究の一部 は宸林漁業試験研究費補助金 (内田蚛太郎) によつた。

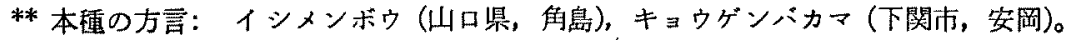


産卵期, 卵および卵内発生

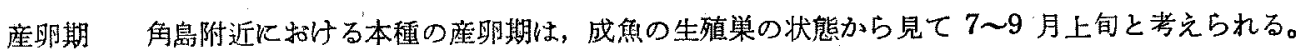

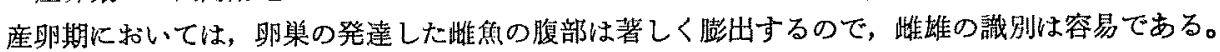

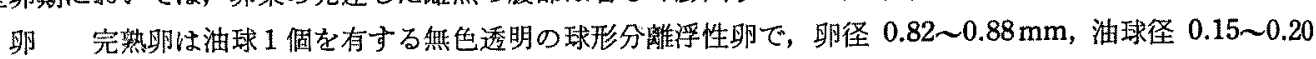
$\mathrm{mm}$ であいた。卵膜には特殊な棈造はないが，畉黄には坵物極の周辺に粗な亀裂がある。卵膜腔は㹟い。

人工授精は 8 月 12 日と 8 月 25 日K，底刺網の㴔隻を用い，漁獲現場で乾導法により行つた。親魯の全長

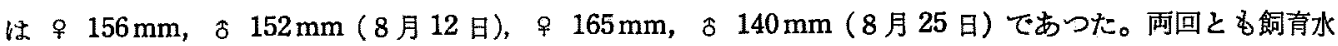
温の差による睬化所要時間には相違があつたが，卵内発生の諸経過は注ば同一であつた。

畉内発生 (Fig. 1, a h) 8 月 25 日午後 11 時 10 分に人工授精を行い，26.8〜28.0 $0^{\circ} \mathrm{C}$ で飼育した場 合について述へる。

受精後 2 時間 20 分に最初の観察を行つたが，卵はすでに Morula 期に達していた（a)。受精直後からこ の間までは舟上で経過したため観察を欠いている。4 時間 50 分後には肧皮は卵黄の $1 / 3$ を掩い，肧体原基 が分化し (c)，8 時間後には肧孔を閉じかけた (d)。8 時間 50 分後には筋肉節 6 個を生じ，眼球括上びKUPFFER 氏胞が認められ，油球は肧体の反対側に位置する（e） 12 時間 30 分後には称肉節 12 個を生じ，頭 部から尼部に至る阫体上K黑色素胞が現われている(f)。13 時間 30 分後にはレンズ，耳䨢拈よび心缄が分 化し，館肉節は 23 個に增加した。肧体上の黑色素胞は数を增し，油球上にも黑色素胞が現われた $(\mathrm{g}, \mathrm{h})$ 。

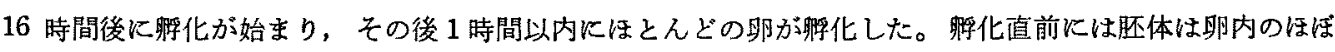

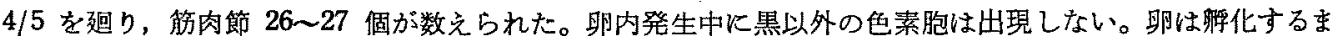
で容器の表層玉たは中層に浮游していた。24〜26 ${ }^{\circ} \mathrm{C}$ の水温では受精後 22 時間 40 分に最初の暚化が見ら れた。

瞬化仔魚 (Fig. 1, i 1) 睬化直後の你 (i) は全長 $1.9 \sim 2.0 \mathrm{~mm}$, 卵黄は長卵形で粗な龟裂があり，

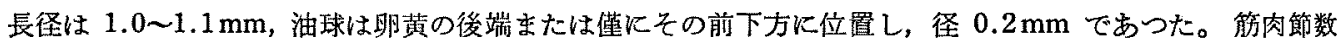
は $12+15=27$ (本種の金椎骨数は $10+14=24$ ), 肚門は体の中央上りやや後飞開く。樹枝状黑色菜胞が 頭頂から尾部後方までの体の背腹面扣よび正中線に沿つてほぼ1列炡び，油球の背面上にも見られる。黄 色素胞は全くない。

娐化後 12 時間の仔魚（j) 全長 $2.32 \mathrm{~mm}$, 胸鯘が現われ, 油球上の黒色素胞が前方へ移る。肛門の位 㯰は体の中央上りやや前方, 筋肉節数は $12+13=25$ 。

睬化後 22 時間の仔魚 $(\mathrm{k})$ 全長 $2.25 \sim 2.45 \mathrm{~mm}$, 畉黄長径 $0.35 \mathrm{~mm}$, 油球径 $0.15 \mathrm{~mm}$, 筋肉節数 10 $+15=25$ 。眼に黒色素胞が現われ始め，体側のるのは大きさを增すが位置はほとんど変らない。油球上の 黑色素胞は卵黄の前方へ移り，油球およびその周辺の卵黄上飞黄色素胞が現われる。腸管背縁括よび腹縁炕 1 2 個の黒色素胞がある個体もある。

脬化後 48 時間の仔魚 (l) 全長 $2.60 \mathrm{~mm}$, 卵黄をほとんど四収し(長径 $0.15 \mathrm{~mm}$ ), 口が開き, 鰓弓の 原基が認められる。胸鯺は大きく発達し，眼も黒くなる。体側の黑色素胞はさらに大きくなり，胸鮨基底部 から尾部後方近くまでの体側一面を掩い，内眼ですこの部分は黒く見える。莭黄上の黄色素胞は袙色し，認 められなくなつた。

娐化後 68 時間には畉黄を吸収し尽し, 死んでいた。

本研究に当り，䅂始御指導を晹わり，かつ本稿の御校閲を頂いた内田恵太郎教授亚びに採集に協力された 苒島漁協の組合員諸氏に深謝の意を表する。

\section{文献}

1) Straughan, R. P. L.: Aquarium J., 30 (9), 338 (1959).

2) 渡部正雄: 資源研短報., No. 11 19, (1946).

3) - : : 資源研堡報., No. 10, 25 (1946).

4) 岡田弹一郎・渡部正雄：動架隹., 57 (3), 29 (1947). 
a

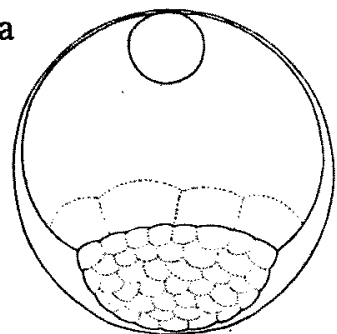

d

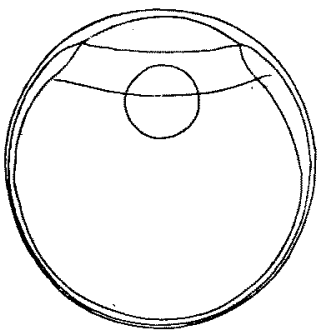

i b

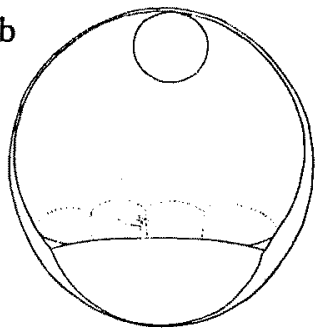

e

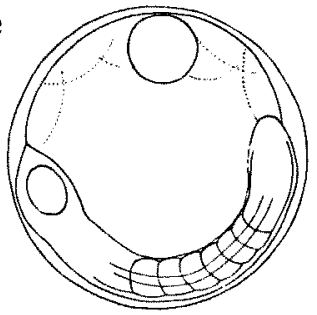

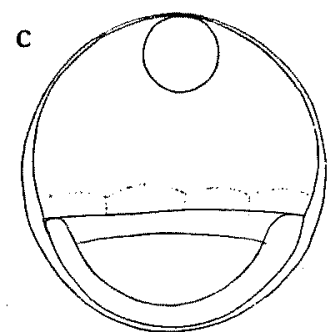
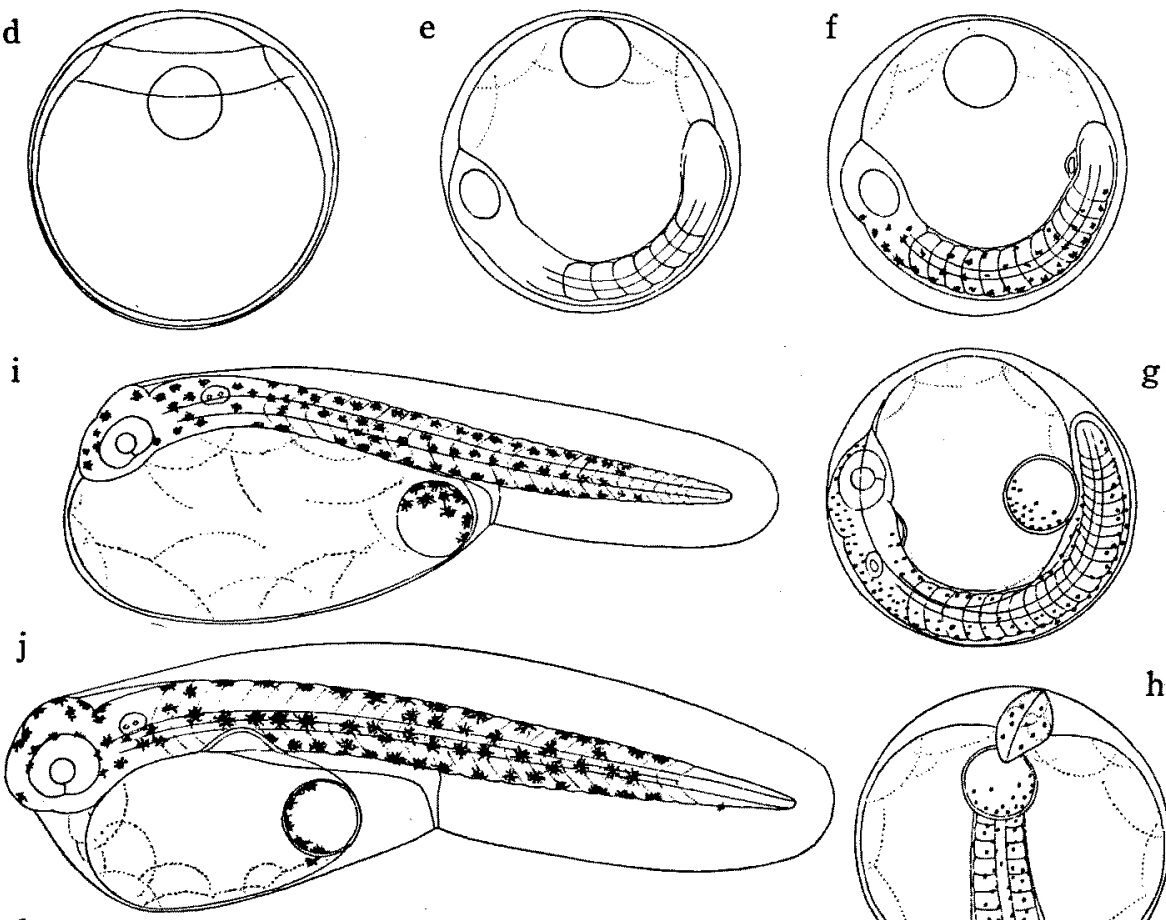

$\mathbf{k}$
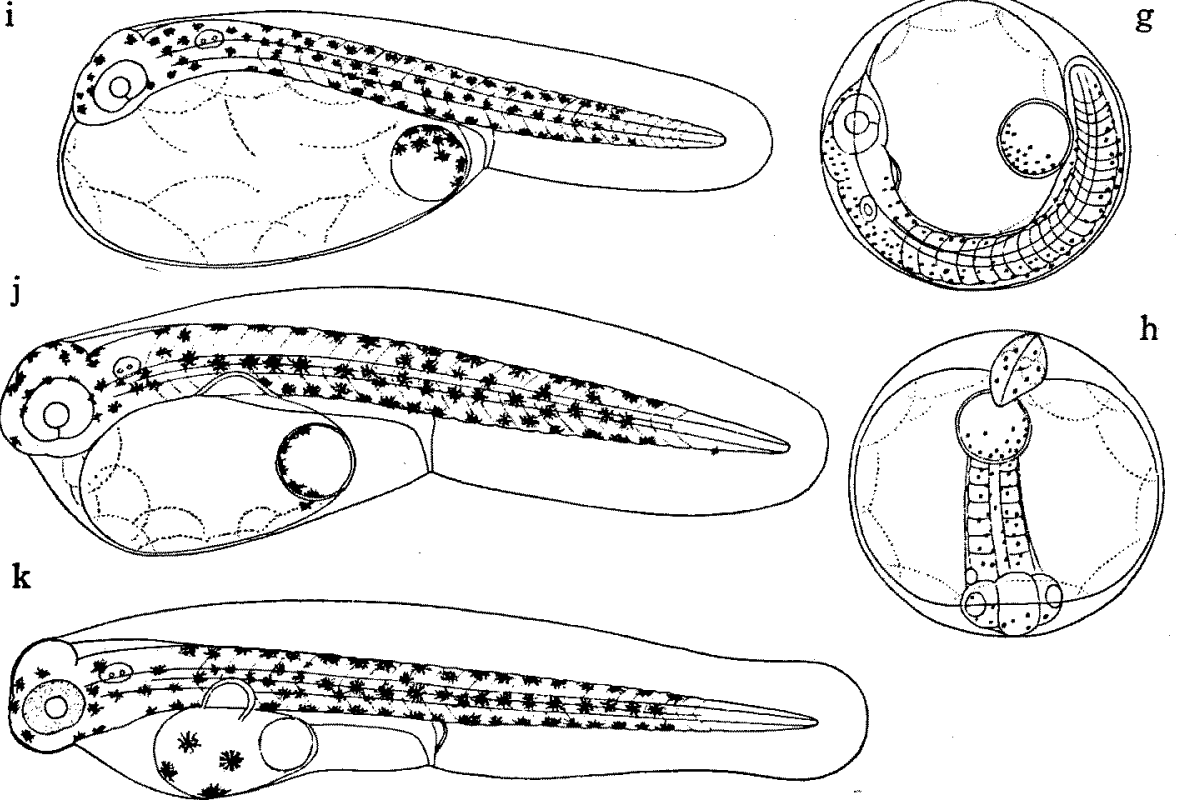

1

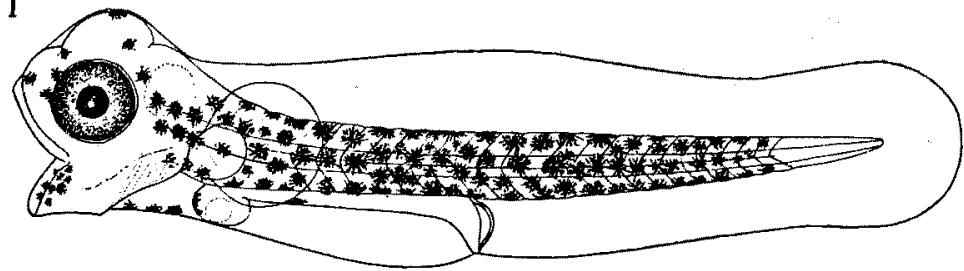

Fig. 1. Develeping eggs and hatched larvae.

a. Morula stage, $2^{\mathrm{h}} 20^{\mathrm{s}}$ after insemination. b. Blastula stage, $3^{\mathrm{h}}$. c. $4^{\mathrm{b}} 50^{\mathrm{m}}$. d. Shortly before the closure of the blastopore, $8^{\mathrm{h}}$. e. 6-myotome stage, $8^{\mathrm{b}} 50^{\mathrm{n}}$. f. 12 -myotome stage, appearance of melanophores, $12^{\mathrm{h}} 30^{\mathrm{m}}$. g, h. 23-myotome stage, 19?. i. Larva just hatched, $1.90 \mathrm{~mm}$ in total length. j. Larva $12^{\mathrm{r}}$ after, $2.32 \mathrm{~mm}$ in total length. k. Larva $22^{\mathrm{h}}$ after, $2.45 \mathrm{~mm}$ in total length. 1. Larva $48^{\mathrm{h}}$ after, $2.60 \mathrm{~mm}$ in total length. $\left(26.8 \sim 28.0^{\circ} \mathrm{C}\right)$ 